\title{
Development of a tool to recognize small airways dysfunction in asthma (SADT)
}

\author{
Lieke Schiphof-Godart ${ }^{1,2 \dagger}$, Erica van der Wiel ${ }^{2,3 \dagger}$, Nick HT ten Hacken ${ }^{2,3}$, Maarten van den Berge ${ }^{2,3}$, \\ Dirkje S Postma ${ }^{2,3+}$ and Thys van der Molen ${ }^{1,2^{*}+}$
}

\begin{abstract}
Background: Small airways dysfunction (SAD) contributes to the clinical expression of asthma. The identification of patients who suffer from SAD is important from a clinical perspective, as targeted therapy may improve patients' well-being and treatment efficacy.
\end{abstract}

Aims: We aimed to realize the first step in the development of a simple small airways dysfunction tool (SADT) that may help to identify asthma patients having SAD.

Methods: Asthma patients with and without SAD were interviewed. Patients were selected to participate in this study based on $\mathrm{FEF}_{50 \%}$ and R5-R20 values from spirometry and impulse oscillometry respectively.

Results: Ten in depth interviews and two focus groups revealed that patients with and without SAD perceived differences in symptoms and signs, habits and health related issues. For example, patients with SAD reported to wheeze easily, were unable to breathe in deeply, mentioned more symptoms related to bronchial hyperresponsiveness, experienced more pronounced exercise-induced symptoms and more frequently had allergic respiratory symptoms after exposure to cats and birds. Based on these differences, 63 items were retained to be further explored for the SADT.

Conclusions: The first step of the development of the SADT tool shows that there are relevant differences in signs and respiratory symptoms between asthma patients with and without SAD. The next step is to test and validate all items in order to retain the most relevant items to create a short and simple tool, which should be useful to identify asthma patients with SAD in clinical practice.

Keywords: Small airways dysfunction, Asthma, Questionnaire

\section{Introduction}

Asthma is one of the most common chronic diseases in people of all ages in developed countries [1]. Frequently reported symptoms are breathlessness, chest tightness, wheeze, cough, limitation of physical activity, and nocturnal awakening. Large airways obstruction due to inflammation and remodeling was traditionally thought to be the origin of these symptoms. However, there is growing consensus that the small airways are also affected, and play a

\footnotetext{
* Correspondence: t.van.der.molen@umcg.nl

${ }^{\dagger}$ Equal contributors

'Department of General Practice, University of Groningen, University Medical Center Groningen, Groningen, the Netherlands

${ }^{2}$ University of Groningen, University Medical Center Groningen, Groningen Research Institute for Asthma and COPD (GRIAC), A. Deusinglaan 1, 9700 AV PO Box 196, Groningen HPC FA 21, The Netherlands

Full list of author information is available at the end of the article
}

role in the clinical expression of asthma [2,3]. A recent systematic review showed that small airways dysfunction (SAD) is associated with worse asthma control, a higher number of exacerbations, the presence of nocturnal asthma, more severe bronchial hyperresponsiveness (BHR) and exercise-induced asthma [4]. Moreover, clinical studies have shown that small particle treatment with inhaled corticosteroids reduces the number of exacerbations and improves asthma control [5-7]. Thus, it has become increasingly important to identify those asthma patients in whom SAD is present. Several tests are available to assess SAD in patients with asthma, like the forced expiratory flow rates at 50 or at 25 to $75 \%$ of the forced vital capacity $\left(\mathrm{FEF}_{50 \%}\right.$ or $\left.\mathrm{FEF}_{25-75 \%}\right)$ which can easily be assessed with spirometry [8-10]. This FEF is closely related to air trapping on an expiratory CT-scan $[11,12]$. In addition, 
impulse oscillometry (IOS) has been used as an easy tool to measure the resistance of the small and large airways [10].

Another method that could help to assess the presence of SAD in asthma patients is by identifying symptoms associated with SAD. These could then be used in a questionnaire to assess both the probability of SAD and the burden of symptoms associated with SAD. So far, it has not been studied whether small or large airways obstruction in asthma generates different symptoms. This may well be the case, since small airways have a smaller lumen size than large airways and lack cartilage. Therefore, smooth muscle contraction may lead to a collapse of the small airways, contributing to air trapping and the perception of chest tightness [13]. Additionally, there is a difference in vagal innervation between the large airways and deeper lung structures, including the small airways $[14,15]$. Finally, not all environmental stimuli are able to reach the small airways. This depends on the particle size, aerodynamic properties and local airway flow characteristics. For instance, cat allergen may reach the peripheral airways, whereas most pollen will never do so because of their large particle size $[16,17]$.
Thus, this study aims to determine which self-reported differences in symptoms might potentially differentiate between asthma patients with SAD and without SAD. In the future, these items might be used to create a tool to recognize SAD in asthma in daily clinical practice, the SADT.

\section{Methods}

\section{Selection of study population}

The participants were selected out of a database of patients attending the Primary Care asthma/COPD service of "Certe Laboratory" (The Netherlands) [18]. This database contains 3,721 patients with a doctor's diagnosis of asthma. We selected asthma patients aged between 18 and 75 years with spirometry according to the American Thoracic Society (ATS) criteria available (Figure 1). This group $(\mathrm{n}=1,578)$ was divided into three groups (tertiles) based on their post-bronchodilator $\mathrm{FEF}_{50 \%}$ percent predicted, in order to select patient populations with and without probable SAD. The $33 \%$ patients $(n=526)$ with the lowest $\mathrm{FEF}_{50 \%}$ represented the group of asthma patients with probable SAD and the $33 \%$ patients $(n=526)$ with the highest $\mathrm{FEF}_{50 \%}$ the group (probably) without SAD. Since a

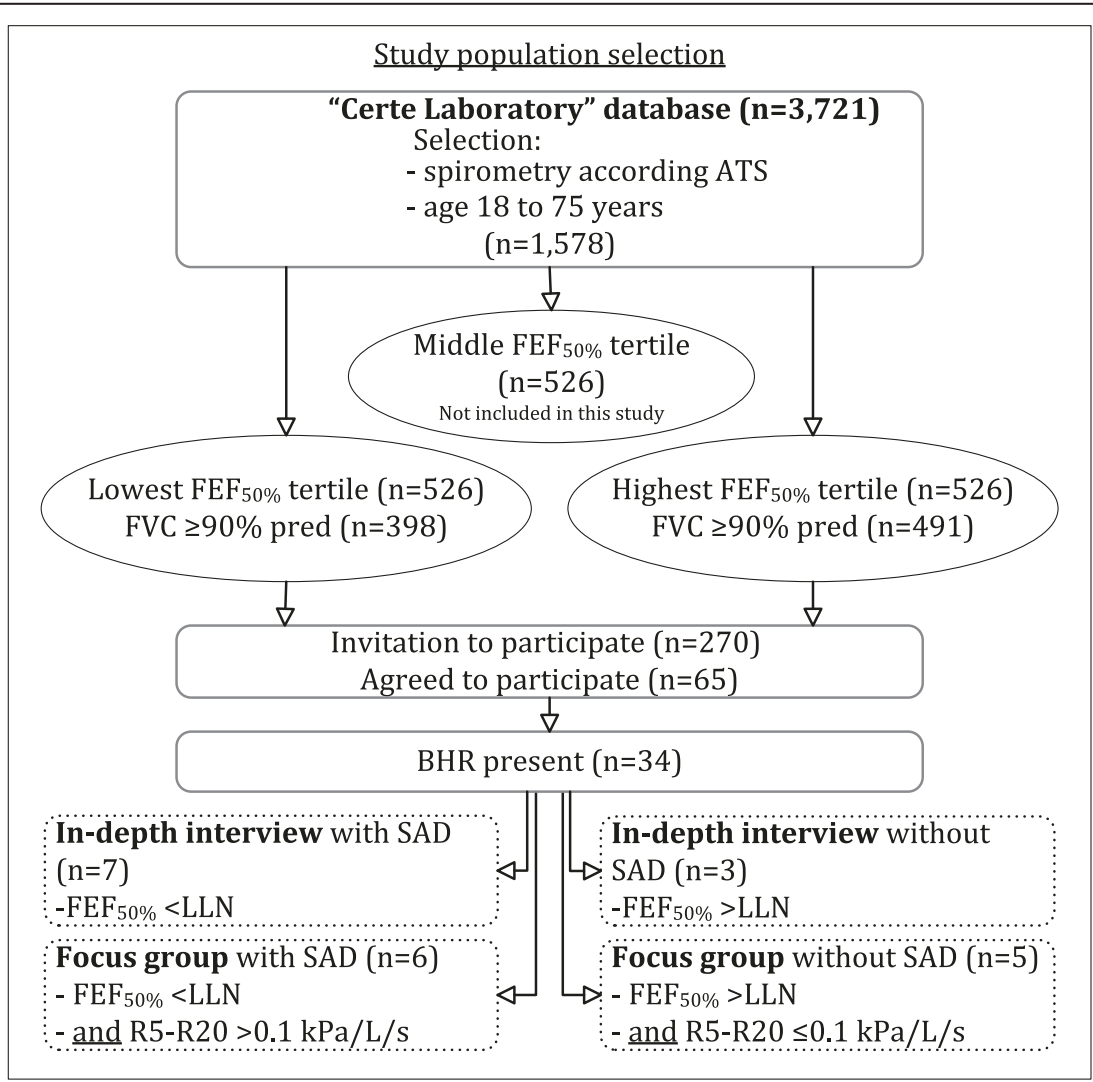

Figure 1 Flowchart of the study with the selection of the study population. ATS: American Thoracic Society, BHR: Bronchial hyperresponsivenesS, $\mathrm{FEV}_{1}=$ Forced expiratory flow in one second, FVC= forced vital capacity, $\mathrm{FEF}_{50 \%}=$ forced expiratory flow at $50 \%$ of the FVC, LLN: lower limit of normal, R5-R20: Difference between the resistance at $5 \mathrm{~Hz}$ and $20 \mathrm{~Hz}$. 
restrictive lung function may lead to low $\mathrm{FEF}_{50 \%}$ predicted values and the false interpretation of existing SAD, we decided to exclude patients with an $\mathrm{FVC}<90 \%$ predicted, leaving 398 patients in the group with SAD and 491 patients in the group without SAD. Characteristics of the source population are shown in Table 1.

General practitioners were contacted and asked for permission to contact their patients eligible for this study. Patient recruitment continued until saturation with respect to content was reached. Finally, 120 patients from the lowest tertile and 150 patients from the highest tertile were invited to participate in this study and a total of 65 patients accepted to participate. They completed the asthma control questionnaire (ACQ), the Clinical COPD Questionnaire (CCQ) and the Bronchial Hyperresponsiveness Questionnaire (BHQ), and performed measurements of spirometry, impulse oscillometry and a methacholine provocation test (methods of the measurements are described in the Additional file 1). Four patients were unable to perform spirometry and were excluded. Patients with BHR $(n=34)$, i.e. a provocative concentration causing a $20 \%$ fall in $\mathrm{FEV}_{1}\left(\mathrm{PC}_{20}\right)$ methacholine bromide $\leq 39.3 \mathrm{mg} / \mathrm{ml}$, were included for further analysis.

\section{In-depth interviews and focus groups}

First, explorative interviews were performed aiming to collect topics for the focus group interviews. For these indepth interviews, 7 patients with and 3 without SAD were selected, based on current $\mathrm{FEF}_{50 \%}$ values lower or higher than the lower limit of normal (LLN). One patient from the highest tertile $\mathrm{FEF}_{50 \%}$ had an $\mathrm{FEF}_{50 \%}$ of $45 \%$ predicted with current spirometry and switched to the group selection with SAD.

Patients were asked about their symptoms, age of asthma onset, possibly related illnesses or allergies and worsening factors or situations such as exercise, weather conditions, psychological stress, and physical fatigue. After 10 in-depth interviews, saturation of topics was attained.

Subsequently, 6 patients with and 5 patients without SAD were identified to attend the focus group interviews. Patients were selected based on a combination of spirometry and IOS measures (Figure 1). Presence of SAD was defined as both $\mathrm{FEF}_{50 \%}<\mathrm{LLN}$ and $\mathrm{R} 5-\mathrm{R} 20>0.10 \mathrm{kPa} / \mathrm{L} / \mathrm{s}$. Absence of SAD was defined as both $\mathrm{FEF}_{50 \%}>\mathrm{LLN}$ and $\mathrm{R} 5-\mathrm{R} 20 \leq 0.10 \mathrm{kPa} / \mathrm{L} / \mathrm{s}$. The cut-off value for R5-R20 was based on a study population of 110 healthy, never or currently smoking subjects, age 18-73 years (NCT00848406; [19]). Of these subjects, $90 \%$ had an R5-R20<0.10 kPa/L/s.

\section{Methods of interviews and focus groups}

All useful topics (items) were selected to be further discussed during the focus group interviews. Discussions in the focus groups were literally and fully transcribed by two authors of this article (LSG and EvdW). Qualitative data management software (NVivo 9 [20]) was used. All items mentioned in the in-depth and focus group interviews were organized in groups of items of interest. Then, a list of all items that differed between SAD and non-SAD patients of the focus groups was created. Afterwards, the list was back- and forward translated by a native English speaking pulmonology expert and two Dutch bilingual primary care researchers with knowledge of pulmonology.

The study and procedures were approved by the medical ethics committee of the University Medical Center Groningen and all patients gave written informed consent.

\section{Results}

The clinical characteristics of the 7 asthma patients with SAD and 3 patients without SAD participating in the individual in-depth interviews are presented in Table 2. Both groups of patients were comparable for most clinical parameters, except $\mathrm{FEV}_{1} / \mathrm{FVC}$ ratio and residual volume (RV). A total of 6 asthma patients with and 5 without

Table 1 Characteristics of source population divided into the lowest and highest $\mathrm{FEF}_{50 \%}$ tertile

\begin{tabular}{|c|c|c|c|c|}
\hline \multirow{3}{*}{ Age (years) } & \multirow{2}{*}{\multicolumn{2}{|c|}{$\frac{\text { Lowest } \mathrm{FEF}_{50 \%} \text { tertile }}{(\mathrm{n}=398)}$}} & \multirow{2}{*}{\multicolumn{2}{|c|}{$\begin{array}{l}\text { Highest } \mathrm{FEF}_{50 \%} \text { tertile } \\
(\mathrm{N}=491)\end{array}$}} \\
\hline & & & & \\
\hline & 54 & (12) & 48 & (13) \\
\hline Gender (\%female) & 72 & & 62 & \\
\hline BMI $\left(\mathrm{kg} / \mathrm{m}^{2}\right)$ & 28 & (5) & 29 & (6) \\
\hline Smoking (\%current/ex/never ) & $26 / 37 / 37$ & & $15 / 42 / 43$ & \\
\hline ICS (\%yes) & 53 & & 50 & \\
\hline $\mathrm{FEV}_{1}$ (\%predicted) & 89 & (9.8) & 109 & (12) \\
\hline $\mathrm{FEV}_{1} / \mathrm{FVC}(\%)$ & 70 & (5.7) & 83 & $(4.3)$ \\
\hline $\mathrm{FEF}_{50 \%}$ (\%predicted) & 51 & (9.9) & 104 & (17) \\
\hline ACQ total score & 1.3 & $(0.9)$ & 1.2 & $(0.9)$ \\
\hline
\end{tabular}

Data presented as mean (SD) or percentage.

$\mathrm{BMI}=$ body mass index, ICS= inhaled corticosteroids, $\mathrm{FEV}_{1}=$ Forced expiratory flow in one second, $\mathrm{FVC}=$ forced vital capacity, $\mathrm{FEF}$ 50\% $=$ forced expiratory flow at $50 \%$ of the FVC, $\mathrm{ACQ}=$ Asthma Control Questionnaire. 
Table 2 Patient characteristics participating in the focus groups

\begin{tabular}{|c|c|c|c|c|c|c|c|c|c|c|}
\hline & \multicolumn{5}{|c|}{ In-depth interview group } & \multicolumn{5}{|c|}{ Focus group } \\
\hline & \multicolumn{2}{|c|}{ With SAD $(n=7)$} & \multicolumn{2}{|c|}{ Without SAD $(n=3)$} & \multirow[b]{2}{*}{ p-value } & \multicolumn{2}{|c|}{ With SAD $(n=6)$} & \multicolumn{2}{|c|}{ Without SAD $(n=5)$} & \multirow[b]{2}{*}{ p-value } \\
\hline & median & (range) & median & (range) & & median & (range) & median & (range) & \\
\hline Age (years) & 45 & $(25-73)$ & 52 & $(20-63)$ & 0.833 & 54 & $(25-73)$ & 47 & $(36-51)$ & 0.247 \\
\hline Gender (female/male) & $5 / 2$ & & $2 / 1$ & & 1.000 & $5 / 1$ & & $4 / 1$ & & 1.000 \\
\hline BMI $\left(\mathrm{kg} / \mathrm{m}^{2}\right)$ & 28 & $(23-39)$ & 36 & $(32-38)$ & 0.117 & 29 & $(23-52)$ & 32 & $(24-38)$ & 0.792 \\
\hline Smoking (current/ex/never\%) & $1 / 4 / 2$ & & $1 / 1 / 1$ & & 0.728 & $0 / 5 / 1$ & & $0 / 1 / 4$ & & 0.080 \\
\hline ICS (yes/no) & $5 / 2$ & & $3 / 0$ & & 1.000 & $4 / 2$ & & $3 / 2$ & & 0.497 \\
\hline $\mathrm{FEV}_{1}$ (\%predicted) & 79 & $(66-104)$ & 99 & $(94-123)$ & 0.117 & 81 & $(76-88)$ & 112 & $(97-127)$ & 0.004 \\
\hline $\mathrm{FEV}_{1} / \mathrm{FVC}(\%)$ & 62 & $(52-73)$ & 83 & $(81-89)$ & 0.017 & 64 & $(52-77)$ & 83 & (80-88) & 0.004 \\
\hline $\mathrm{FEF}_{50 \%}$ (\%predicted) & 37 & $(23-62)$ & 107 & $(89-115)$ & NA & 40 & $(23-55)$ & 114 & $(82-122)$ & NA \\
\hline RV (\%predicted) & 120 & $(88-160)$ & 72 & $(71-89)$ & 0.033 & 120 & $(88-160)$ & 88 & (77-98) & 0.017 \\
\hline IOS R20 (kPa/l/s) & 0.39 & $(0.29-0.50)$ & 0.33 & $(0.32-0.40)$ & 0.517 & 0.39 & $(0.34-0.67)$ & 0.38 & $(0.26-0.49)$ & 0.429 \\
\hline IOS R5-R20 (kPa/l/s) & 0.27 & $(0.10-0.44)$ & 0.19 & $(0.11-0.25)$ & 0.383 & 0.25 & $(0.14-0.29)$ & 0.05 & $(0.01-0.08)$ & NA \\
\hline IOS X5 (kPa/l/s) & -0.22 & $(-0.49 ;-0.12)$ & -0.23 & $(-0.26 ;-0.11)$ & 1.000 & -0.23 & $(-0.49 ;-0.22)$ & -0.07 & $(-0.12 ;-0.06)$ & 0.004 \\
\hline $\mathrm{PC}_{20}$ methacholine $\mathrm{A}^{\#}(\mathrm{mg} / \mathrm{ml})$ & 1.1 & $(0.1-6.4)$ & 3.5 & $(1.3-23.9)$ & 0.183 & 1.13 & $(0.14-5.55)$ & 9.8 & $\left(2.8-20.9^{@}\right)$ & 0.017 \\
\hline ACQ (total score) & 0.5 & $(0.0-1.5)$ & 2.0 & $(0.0-2.2)$ & 0.383 & 0.6 & $(0.0-1.3)$ & 1.0 & $(0.3-2.2)$ & 0.177 \\
\hline BHQ symptoms (score) & 0.4 & $(0.0-2.5)$ & 1.8 & $(0.3-3.1)$ & 0.383 & 1.3 & $(0.0-2.7)$ & 1.9 & $(1.3-2.7)$ & 0.329 \\
\hline BHQ stimuli (score) & 1.2 & $(0.0-4.3)$ & 1.8 & $(0.0-4.3)$ & 0.833 & 2.5 & $(0.1-3.8)$ & 2.5 & $(0.9-4.1)$ & 0.662 \\
\hline
\end{tabular}

${ }^{\circledR}$ Patient with a $\mathrm{PC}_{20} 20.9 \mathrm{mg} / \mathrm{ml}$ methacholine used $800 \mu \mathrm{g}$ ICS. "Values were log transformed. Differences were tested with a non-parametric test. For ordinal variables differences were tested with the Fisher's Exact test or Chi-square test as appropriate.

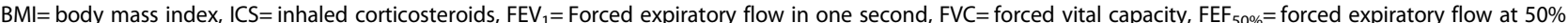
of the FVC, RV= residual volume, IOS= impulse oscillometry, R20: Resistance of the respiratory system at 20 Hertz, R5-R20: Difference between the resistance at $5 \mathrm{~Hz}$ and $20 \mathrm{~Hz}, \mathrm{X} 5=$ Reactance of the respiratory system at $5 \mathrm{Hertz}, \mathrm{PC}_{20}=$ provocative concentration causing a $20 \%$ fall in $\mathrm{FEV}$, $\mathrm{ACQ}=\mathrm{Asthma}$ Control Questionnaire, $\mathrm{BHQ}=$ Bronchial Hyperresponsiveness Questionnaire.

SAD participated in the focus groups (Table 2). No differences between the group with and without SAD were observed in most parameters, except for lung function parameters. Four patients of the SAD focus group had also participated in the individual in-depth interviews. Patients participating in the in-depth interview or focus group did not use small particle inhalation medication.

\section{Item organization and selection}

All items that appeared to be different between the two groups were selected and a total of 63 items was retained. All items were phrased in a positive way (for example "I have an immediate reaction to cats"). Of these phrases, 21 phrases were in line with symptoms of patients with SAD and not of patients without SAD (e.g. "When I feel asthmatic, I feel it in my chest."), whereas 41 phrases were in line with symptoms of patients without SAD (e.g. "I frequently have a hoarse or husky voice"). In addition one open question ("At what age did you first suffer from asthma symptoms?") was added. The resulting 63 items are shown in Table 3 and are divided in the following 10 domains.

1. The Asthma Symptoms domain (13 items); patients with SAD reported to wheeze more often and more easily. All patients with SAD were unable to breathe in deeply when having asthma symptoms, while this was not reported by any of the patients without SAD.

2. The Ears, Nose and Throat domain (10 items); these symptoms were only mentioned by patients without SAD.

3. The Localization of Symptoms domain (6 items) includes items concerning the exact spot of pain and other signs when feeling asthmatic. SAD patients for example mentioned an oppressive feeling and pain in the chest, whereas patients without SAD felt bloated and sometimes had pain in the middle or the upper part of the back.

4. The BHR to Exercise domain (8 items); patients with SAD mentioned problems with regular physical activities, while those without SAD were rarely hindered in their activities.

5. The BHR to Allergens domain (4 items) shows that patients with SAD react to birds and cats, while those without SAD cannot stand wool or down.

6. The BHR to Weather Changes domain (6 items) reflects that both groups seem to react to weather changes, but in a different way.

7. The Stress and Fatigue domain (7 items); patients with SAD reported more asthma symptoms in 
Table 3 63-items of the SADT

\begin{tabular}{|c|c|}
\hline & Without SAD \\
\hline \multirow[t]{7}{*}{ Domain 1: Asthma symptoms } & $\begin{array}{l}\text { Concentrating on my breathing helps me when } \\
\text { I feel asthmatic. }\end{array}$ \\
\hline & $\begin{array}{l}\text { People often tell me they can hear me breathing, } \\
\text { even in a calm situation. }\end{array}$ \\
\hline & I only wheeze when I feel very asthmatic. \\
\hline & I often cough unexpectedly. \\
\hline & $\begin{array}{l}\text { I often cough superficially (tickling cough) before } \\
\text { I get bothered by coughing more deeply. }\end{array}$ \\
\hline & I can see it coming when I get my asthma. \\
\hline & $\begin{array}{l}\text { I often have a period without feeling asthmatic and } \\
\text { without needing rescue puffs. }\end{array}$ \\
\hline \multirow{9}{*}{$\begin{array}{l}\text { Domain 2: Ear/nose/ throat } \\
\text { complaints }\end{array}$} & My asthma symptoms are preceded by the flu or a cold. \\
\hline & $\begin{array}{l}\text { When I feel asthmatic, I almost always have symptoms } \\
\text { comparable to a cold. }\end{array}$ \\
\hline & I usually get a cold first, and thereafter start coughing. \\
\hline & I often suffer with my ears. \\
\hline & I often have runny or painful eyes without having hay fever. \\
\hline & I frequently have a hoarse or husky voice. \\
\hline & $\begin{array}{l}\text { When I feel asthmatic, it often comes with symptoms of } \\
\text { my throat, nose, ears or eyes. }\end{array}$ \\
\hline & When I feel asthmatic, I often, also suffer from a sore throat. \\
\hline & My tonsils or adenoids have been removed. \\
\hline Domain 3. I ocalization of sv & When I feel asthmatic I feel it in the middle of my back \\
\hline
\end{tabular}

\section{With SAD}

I'm not able to breathe in deeply

when I feel asthmatic.

I sometimes wheeze when I'm at ease or in rest.

When I'm physically active (like walking the stairs), I sometimes wheeze.

I can feel suddenly asthmatic without having any other symptoms.

I almost always feel slightly asthmatic and I take a rescue puff regularly.

I have suffered from bronchitis.

I usually have runny or painful eyes when I have hay fever.
Domain 4: BHR to exercise

Domain 5: BHR to allergens

Domain 6: BHR to weather changes

Domain 7: Stress and fatigue
When I feel asthmatic, I feel it in the top of my back.

When I feel asthmatic, I feel a stab or a sting in my back or my ribs.

When I feel asthmatic, I sometimes feel bloated.

As a child, I always participated in all games and sports.

I am able to walk a long distance without resting.

When I'm not ill, I can easily do physical activities such as walking the stairs.

When I feel asthmatic when exercising, it is very often due to the environment (grass, trees, flowers...).

When I feel asthmatic when exercising, it is very often due to the weather.

Sometimes I go running or jogging.

I cannot stand woolen blankets or clothes.

I cannot stand the down filling in pillows.

I tire more rapidly due to weather changes.

My breathing becomes easier in cold air.

I always sleep with an open window, otherwise I feel asthmatic.

I rapidly get tired due to my asthma symptoms.
When I feel asthmatic, I have a pressing and oppressive feeling.

When I feel asthmatic, I feel it in my chest.

Actually, I cannot perform strenuous exercise or sport, because I will become asthmatic.

Physical activities always make my asthma worse.
I have an immediate reaction to birds.

I have an immediate reaction to cats. My asthma worsens in autumn.

I feel asthmatic more rapidly due to weather changes.

I feel asthmatic when I suddenly enter a cold environment.

In stressful situations, I get particularly asthma symptoms. 


\begin{tabular}{|c|c|c|}
\hline & $\begin{array}{l}\text { Feeling tired is as much part of my asthma as } \\
\text { feeling short of breath. }\end{array}$ & $\begin{array}{l}\text { In stressful situations I have physical symptoms } \\
\text { such as complaints of the nose, throat or voice. }\end{array}$ \\
\hline $\begin{array}{l}\text { When I'm feeling tired I will } \\
\text { probably get asthmatic in } \\
\text { a few days. }\end{array}$ & I tire more rapidly due to my asthma symptoms. & \\
\hline \multicolumn{3}{|l|}{$\begin{array}{l}\text { When I feel asthmatic, I often, also } \\
\text { have a headache. }\end{array}$} \\
\hline \multirow[t]{3}{*}{ Domain 8: Gastro-intestinal tract } & $\begin{array}{l}\text { Sometimes I feel asthmatic or out of breath } \\
\text { because of heartburn. }\end{array}$ & \\
\hline & $\begin{array}{l}\text { Sometimes, when I'm short of breath, it can } \\
\text { be a relief to burp. }\end{array}$ & \\
\hline & $\begin{array}{l}\text { Sometimes I have stomach problems which } \\
\text { can make me feel asthmatic. }\end{array}$ & \\
\hline \multirow[t]{3}{*}{ Domain 9: Skin } & & I get eczema because of weather changes. \\
\hline & & $\begin{array}{l}\text { I get skin problems (like eczema) when touching } \\
\text { some kinds of food (e.g. fruit or vegetables). }\end{array}$ \\
\hline & & My asthma symptoms and eczema alternate. \\
\hline \multirow[t]{3}{*}{ Domain 10: Miscellaneous } & I often get car sick or travel sick. & \\
\hline & $\begin{array}{l}\text { I have more than three close relatives suffering } \\
\text { from asthma or comparable illnesses. }\end{array}$ & \\
\hline & $\begin{array}{l}\text { At what age did you first suffer from asthma } \\
\text { symptoms? }\end{array}$ & \\
\hline
\end{tabular}

relation to stress, while patients without SAD reported more asthma symptoms related to periods of fatigue.

8. The Gastrointestinal Complaints domain (3 items); Patients without SAD mentioned to suffer sometimes from gastrointestinal problems related to their asthma, but asthma patients with SAD did not.

9. The Skin problems domain (3 items); only patients with SAD reported eczema related to asthma.

10. The last domain (3 items) was named Miscellaneous. Patients without SAD reported often getting car-sick and having asthmatic relatives. Patients with SAD reported to be somewhat older when their first symptoms appeared. These items did not combine with any other domains and were thus placed in this last domain.

\section{Discussion}

This is the first phase of the development of a questionnaire aiming to help identifying asthma patients with SAD based on self-reported symptoms in clinical practice. Based on the differences that we found after ten indepth interviews and two focus groups in patients with and without SAD, we identified a total of 63 items that may help to differentiate between patients with and without SAD. In short, we found that patients with SAD reported to wheeze easily, were unable to breathe in deeply, mentioned more symptoms related to BHR, experienced more pronounced exercise-induced symptoms and more frequently had allergic respiratory symptoms after exposure to cats and birds.

Interestingly, a number of the observed differences between patients with and without SAD, are supported by recent observations reported in the literature [21-31]. Our finding that patients with SAD were unable to breathe in deeply and reported to wheeze very easily may reflect hyperinflation, compatible with small airway closure. Mansur et al. also found a relationship between more symptoms of wheezing and more severe small airways dysfunction during a methacholine provocation test [21]. In addition, patients with SAD indicated that they had suffered from bronchitis at least once in their life, whereas patients without SAD did not. More frequent symptoms and need of rescue treatment are compatible with worse asthma control and the occurrence of asthma exacerbations, findings that have been related to SAD in asthma in previous studies as well [22-24].

Patients with SAD also reported more frequently symptoms of BHR to exercise, allergens and weather changes (domains 4, 5 and 6). This is compatible with earlier studies on BHR showing that hyperresponsiveness is associated with small airways obstruction in asthma [25-27]. Interestingly, Zeidler et al. showed that patients with allergic asthma exposed to cat allergens have predominantly a response of the small airways measured by HRCT scan [28]. Our asthma patients with SAD reported an immediate and strong response to cats. Indeed, these allergens can be found on rather small particles (diameter $<2.5 \mu \mathrm{m}$ ), 
probably affecting asthma patients with SAD more than patients without SAD [29]. In contrast, patients without SAD reported to respond strongly to wool and down. This might be related to house dust-mite excretion in these tissues, which is found on larger particles $(10 \mu \mathrm{m})$ [30]. Exercise induced symptoms were predominantly mentioned by patients with SAD, which is in line with a study of Lee et al. showing an association between the severity of exercise-induced response and an increased resistance of the small airways [31].

For some of the observed differences between patients with and without SAD we have not found corresponding findings in the existing literature. These novel findings might be interesting to study in a more systematic way in further research regarding symptoms of SAD in asthma.

Our patients represent the asthma population as present in the original primary care database of the asthma COPD service from "Certe Laboratory". Included patients had a median age of 51 years and a median BMI of $30 \mathrm{~kg} / \mathrm{m}^{2}$, $77 \%$ of the patients being female, whereas the asthmapopulation of the primary care database had a mean age of 53 with a mean BMI of $29 \mathrm{~kg} / \mathrm{m}^{2}$ and consisted of $68 \%$ females. The smoking habits of our study population, i.e. $12 / 47 / 41 \%$ current/never/ex smokers, were comparable with the asthma-population of the primary care database. Thus the final list of 63 items is not limited to nonsmokers. This is of importance since a few studies have suggested an important effect of smoking on SAD [32,33]. With exclusion of smokers we could have missed signs and symptoms important for SAD.

The study has some limitations. The scientific community has so far not provided an agreed gold standard for the diagnosis of SAD in asthma. We did not use Computed Tomography (CT scan) or multiple breath nitrogen washout tests to assess the presence of small airways disease, yet we used a very precise way of selecting and reselecting patients with and without SAD, based on a combination of both $\mathrm{FEF}_{50 \%}$ and $\mathrm{R} 5-\mathrm{R} 20$ values. These parameters are frequently described as a reliable way to assess $\operatorname{SAD}[8,10]$. The division in patients below and above the LLN of the $\mathrm{FEF}_{50 \%}$ has also been used in a previous study to compare patients with and without SAD [26]. For the R5-R20 we used a cutoff value that was based on a group of 110 well selected and well characterized healthy controls [19].

In summary, the present study is a first step in the development of the SADT. We generated 63 items for the new small airways dysfunction tool, the SADT, which aims to identify patients with SAD. The items that were identified cover a broad area of asthma symptoms related to airway hyperresponsiveness, response to allergens and physical exercise. All generated items will be further tested and validated in a large asthma population with a wide spectrum of severity during a multinational longitudinal study that will start in the near future. The next study will retain the most relevant items with which a short and simple tool to determine SAD in asthma patients will be realized.

\section{Clinical implications}

Identification of SAD in asthma patients may be possible using this simple and non-invasive tool. Differences in symptoms and signs between asthma patients with and without SAD were identified.

\section{Capsule summary}

Based on differences in symptoms and signs, habits and health related issues between asthma patients with and without SAD, 63 items were combined to be entered in the next phase of the SADT.

\section{Additional file}

Additional file 1: Measurement specifications.

\section{Abbreviations}

ACQ: Asthma Control Questionnaire; ATS: American Thoracic Society; AX: Reactance area; BHR: Bronchial hyperresponsiveness; BHQ: Bronchial Hyperresponsiveness Questionnaire; BMI: Body mass index; CCQ: Clinical

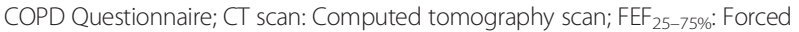
expiratory flow at $25 \%$ to $75 \%$ of $\mathrm{FVC}_{\text {; }} \mathrm{FEF}_{50 \%}$ : Forced expiratory flow at $50 \%$ of FVC; FEV 1 : Forced expiratory flow in one second; FVC: Forced vital capacity; IOS: Impulse oscillometry; IQ: Interquartile; LLN: Lower limit of normal; $\mathrm{NCT}$ : Clinical trial registry number; $\mathrm{PC}_{20}$ : Provocative concentration causing a 20\% fall in $\mathrm{FEV}_{1}$; X5: Reactance of the respiratory system at 5 Hertz; R5: Resistance of the respiratory system at 5 Hertz; R20: Resistance of the respiratory system at 20 Hertz; R5-R20: Difference of R5 minus R20; RV: Residual volume; SAD: Small airways dysfunction; SADT: Small Airways Dysfunction Tool.

\section{Competing interests}

Dr. Schiphof-Godart and dr. van der Wiel have no competing interests to declare. MvdB reports research grants to the University of Groningen from Chiesi, TEVA, GlaxoSmithKline, and AstraZeneca, outside the submitted work. $\mathrm{NtH}$ reports research grants to the University from Chiesi and GlaxoSmithKline. TvdM received funding for research from Astra Zeneca, GlaxoSmithKline and Boehringer Ingelheim. TvdM also received reimbursement for presentations and consultancy from TEVA, GlaxoSmithKline, Boehringer Ingelheim and Astra Zeneca. The University of Groningen has received money for Professor Postma regarding an unrestricted educational grant for research from Astra Zeneca and Chiesi. Professor Postma also received travel fees and/or consultancy fees from Boehringer Ingelheim, Chiesi, GSK, Takeda, Astra Zeneca, Chiesi, GSK, Takeda and TEVA.

\section{Authors' contributions}

EvdW, LSG, DSP, and TVdM contributed to data collection and patient recruitment. EvdW and LSG performed the data analyses and EvdW, DSP, $\mathrm{NtH}$ and MvdB were involved in interpretation of the data. LSG and EvdW wrote the manuscript supervised by MvdB, NtH, DSP and TvdM. All authors contributed to the writing of the article and critically reviewed and approved the final version.

\section{Acknowledgment}

We are grateful to Chiesi for an unrestricted educational grant on small airway disease. Chiesi was in no way involved in study design, writing or reviewing of the manuscript.

\section{Author details}

'Department of General Practice, University of Groningen, University Medical Center Groningen, Groningen, the Netherlands. 'University of Groningen, University Medical Center Groningen, Groningen Research Institute for 
Asthma and COPD (GRIAC), A. Deusinglaan 1, 9700 AV, PO Box 196, Groningen HPC FA 21, The Netherlands. ${ }^{3}$ Department of Pulmonary Medicine and Tuberculosis, University of Groningen, University Medical Center Groningen, Groningen, the Netherlands.

Received: 29 October 2013 Accepted: 9 October 2014

Published online: 22 November 2014

\section{References}

1. Bateman ED, Hurd SS, Barnes PJ, Bousquet J, Drazen JM, FitzGerald M, Gibson P, Ohta K, O'Byrne P, Pedersen SE, Pizzichini E, Sullivan SD, Wenzel SE, Zar HJ: Global strategy for asthma management and prevention: GINA executive summary. Eur Respir J 2008, 31(1):143-178.

2. van den Berge M, ten Hacken NH, Cohen J, Douma WR, Postma DS: Small airway disease in asthma and COPD: clinical implications. Chest 2011, 139(2):412-423.

3. Farah CS, King GG, Brown NJ, Downie SR, Kermode JA, Hardaker KM, Peters MJ, Berend N, Salome CM: The role of the small airways in the clinical expression of asthma in adults. J Allergy Clin Immunol 2012, 129(2):381-7, 387.e1.

4. van der Wiel E, ten Hacken NH, Postma DS, van den Berge M: Small-airways dysfunction associates with respiratory symptoms and clinical features of asthma: a systematic review. J Allergy Clin Immunol 2013, 131(3):646-657.

5. Colice G, Martin RJ, Israel E, Roche N, Barnes N, Burden A, Polos P, Dorinsky P, Hillyer EV, Lee AJ, Chisholm A, von Ziegenweidt J, Barion F, Price D: Asthma outcomes and costs of therapy with extrafine beclomethasone and fluticasone. J Allergy Clin Immunol 2013, 132(1):45-54.

6. Barnes N, Price D, Colice G, Chisholm A, Dorinsky P, Hillyer EV, Burden A, Lee AJ, Martin RJ, Roche N, von Ziegenweidt J, Israel E: Asthma control with extrafine-particle hydrofluoroalkane-beclometasone vs. largeparticle chlorofluorocarbon-beclometasone: a real-world observational study. Clin Exp Allergy 2011, 41(11):1521-1532.

7. van den Berge M, ten Hacken NH, van der Wiel E, Postma DS: Treatment of the bronchial tree from beginning to end: targeting small airway inflammation in asthma. Allergy 2013, 68(1):16-26.

8. Scichilone N, Battaglia S, Olivieri D, Bellia V: The role of small airways in monitoring the response to asthma treatment: what is beyond FEV1? Allergy 2009, 64(11):1563-1569.

9. Bar-Yishay E, Amirav I, Goldberg S: Comparison of maximal midexpiratory flow rate and forced expiratory flow at $50 \%$ of vital capacity in children. Chest 2003, 123(3):731-735.

10. Contoli M, Bousquet J, Fabbri LM, Magnussen H, Rabe KF, Siafakas NM, Hamid Q, Kraft M: The small airways and distal lung compartment in asthma and COPD: a time for reappraisal. Allergy 2010, 65(2):141-151

11. Ueda T, Niimi A, Matsumoto H, Takemura M, Hirai T, Yamaguchi M, Matsuoka H, Jinnai M, Muro S, Chin K, Mishima M: Role of small airways in asthma: investigation using high-resolution computed tomography. J Allergy Clin Immunol 2006, 118(5):1019-1025.

12. Lucidarme O, Coche E, Cluzel P, Mourey-Gerosa I, Howarth N, Grenier P. Expiratory CT scans for chronic airway disease: correlation with pulmonary function test results. AJR Am J Roentgenol 1998, 170(2):301-307.

13. Lougheed MD, Fisher T, O'Donnell DE: Dynamic hyperinflation during bronchoconstriction in asthma: implications for symptom perception. Chest 2006, 130(4):1072-1081.

14. Burki NK, Lee LY: Mechanisms of dyspnea. Chest 2010, 138(5):1196-1201.

15. Undem BJ, Nassenstein C: Airway nerves and dyspnea associated with inflammatory airway disease. Respir Physiol Neurobiol 2009, 167(1):36-44.

16. Lieutier-Colas F, Purohit A, Meyer P, Fabries JF, Kopferschmitt MC, Dessanges JF, Pauli G, de Blay F: Bronchial challenge tests in patients with asthma sensitized to cats: the importance of large particles in the immediate response. Am J Respir Crit Care Med 2003, 167(8):1077-1082.

17. Riediker M, Koller T, Monn C: Differences in size selective aerosol sampling for pollen allergen detection using high-volume cascade impactors. Clin Exp Allergy 2000, 30(6):867-873.

18. van der Molen T, Riemersma RA, van Heijst E, Meijer R: Astma/COPD-ketenzorg in de provincie Groningen. Caravisie 2007, 20(3):9-13.

19. Telenga ED, Keulers L, Ten Hacken NHT, Postma DS, Van den Berge M: ERS abstract: Indications of small airways disease in healthy smokers. 2012. P3448(P3448).

20. Nvivo research software for analysis and insight: Nvivo Research Software for Analysis and Insight. QSR international Pty Ltd; 2012. 2013; 2012. Available at: http://www.qsrinternational.com/contact.aspx.
21. Mansur AH, Manney S, Ayres JG: Methacholine-induced asthma symptoms correlate with impulse oscillometry but not spirometry. Respir Med 2008, 102(1):42-49.

22. Thompson BR, Douglass JA, Ellis MJ, Kelly VJ, O'Hehir RE, King GG, Verbanck S: Peripheral lung function in patients with stable and unstable asthma. J Allergy Clin Immunol 2013, 131(5):1322-1328.

23. in 't Veen JC, Beekman AJ, Bel EH, Sterk PJ: Recurrent exacerbations in severe asthma are associated with enhanced airway closure during stable episodes. Am J Respir Crit Care Med 2000, 161(6):1902-1906.

24. Rao DR, Gaffin JM, Baxi SN, Sheehan WJ, Hoffman EB, Phipatanakul W: The utility of forced expiratory flow between $25 \%$ and $75 \%$ of vital capacity in predicting childhood asthma morbidity and severity. J Asthma 2012, 49(6):586-592.

25. Currie GP, Jackson CM, Lee DK, Lipworth BJ: Determinants of airway hyperresponsiveness in mild asthma. Ann Allergy Asthma Immunol 2003, 90(5):560-563

26. Telenga ED, van den Berge $M$, Ten Hacken $\mathrm{NH}$, Riemersma RA, van der Molen $T$, Postma DS: Small airways in asthma: their independent contribution to the severity of hyperresponsiveness. Eur Respir J 2013, 41(3):752-754.

27. Downie SR, Salome CM, Verbanck S, Thompson B, Berend N, King GG: Ventilation heterogeneity is a major determinant of airway hyperresponsiveness in asthma, independent of airway inflammation. Thorax 2007, 62(8):684-689.

28. Zeidler MR, Goldin JG, Kleerup EC, Kim HJ, Truong DA, Gjertson DW, Kennedy NJ, Newman KB, Tashkin DP, Silverman JM, Corren J: Small airways response to naturalistic cat allergen exposure in subjects with asthma. J Allergy Clin Immunol 2006, 118(5):1075-1081.

29. Luczynska CM, Li Y, Chapman MD, Platts-Mills TA: Airborne concentrations and particle size distribution of allergen derived from domestic cats (Felis domesticus). Measurements using cascade impactor, liquid impinger, and a two-site monoclonal antibody assay for Fel d I. Am Rev Respir Dis 1990, 141(2):361-367.

30. Tovey ER, Chapman MD, Wells CW, Platts-Mills TA: The distribution of dust mite allergen in the houses of patients with asthma. Am Rev Respir Dis 1981, 124(5):630-635.

31. Lee JH, Lee YW, Shin YS, Jung YH, Hong CS, Park JW: Exercise-induced airway obstruction in young asthmatics measured by impulse oscillometry. J Investig Allergol Clin Immunol 2010, 20(7):575-581.

32. Cosio M, Ghezzo H, Hogg JC, Corbin R, Loveland M, Dosman J, Macklem PT: The relations between structural changes in small airways and pulmonary-function tests. N Engl J Med 1978, 298(23):1277-1281.

33. Contoli M, Kraft M, Hamid Q, Bousquet J, Rabe KF, Fabbri LM, Papi A: Do small airway abnormalities characterize asthma phenotypes? In search of proof. Clin Exp Allergy 2012, 42(8):1150-1160

doi:10.1186/s12955-014-0155-7

Cite this article as: Schiphof-Godart et al:: Development of a tool to recognize small airways dysfunction in asthma (SADT). Health and Quality of Life Outcomes 2014 12:155.

\section{Submit your next manuscript to BioMed Central and take full advantage of:}

- Convenient online submission

- Thorough peer review

- No space constraints or color figure charges

- Immediate publication on acceptance

- Inclusion in PubMed, CAS, Scopus and Google Scholar

- Research which is freely available for redistribution 